\title{
Water and Wastewater Utility Affordability - The Cape Coral Florida Experience
}

Donald A. Forrer, D.B.A., Hodges University, USA

Charles Ehart, D.P.A., Hodges University, USA

Acie S. Forrer, Doctoral Student - University of Maryland - University College, USA

\begin{abstract}
This study describes the trials and tribulations of a growing city involved in maintaining utility rates at an affordable level while completing a one billion dollar utility expansion. Emphasis is on the political and financial issues faced by management. This research deals exclusively with utility rate issues within the City of Cape Coral Florida during rapid growth and utility expansion. The analysis alludes to issues with affordability when the expansion is stopped, but bonds for a new water plant must be paid.
\end{abstract}

Keywords: utility rates; rate model; municipal bonds; debt service; city government

\section{INTRODUCTION}

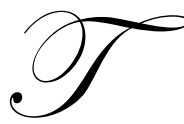

he City of Cape Coral Florida provides a unique challenge. Less than fifty (50) years old, the City was truly swamp land in Florida that became a beautiful city with approximately 400 miles of both saltwater and freshwater canals. In fact, there is a book written about the City titled: "The lie that came true." This case study describes the trials and tribulations of a growing city involved in a massive utility expansion program. Emphasis is on financial issues faced by management. This research deals exclusively with utility rate issues within the City of Cape Coral Florida.

The original developers platted the City into 10,000 square foot building sites. These sites were marketed world-wide. Although there are limited properties with larger square footage, economic development is difficult due to the problem of accumulating land. Available land is held by a few individuals. For many reasons, the City of cape Coral is a unique case study.

The overall purpose of this research is to analyze the development of a water and wastewater rate study for a publicly operated municipality. According to Gerasimos and Wang (2003), an effective utility rate model must address four issues; 1) revenues must cover costs, 2) price structure should encourage conservation, 3) revenue must be stable, and 4) administrative costs associated with collecting the revenue should be as low as possible. Building a solid model that addresses these four issues will enable governmental agencies to maintain confidence of consumers and provide a service to the public.

As indicated in this research, the purpose of a utility rate study is to allocate costs according to the classification of customers. It is imperative that entities are treated fairly. Commercial property, single-family homes, apartments, condos, use services differently. It is important to ensure that rates are fairly distributed among user classes. A successful rate study provides the municipality with the ability to base charges for services on the true cost to each user classification.

\section{LITERATURE REVIEW - UTILITY RATES IN GENERAL}

Rajah and Smith (1993) studied pricing models in Great Britian and suggested that municipalities select from five fiscal models to determine pricing. England utilizes similar variables as those utilized in the United States. Capacity and commodity charges are levied and charges are based on usage in most cases. Rajad and Smith 
emphasize that efficiency in pricing and administration is an important element when managing water utilities. Their five models include: 1) a license fee where all users pay exactly the same amount, 2) metered charges based on consumption, 3) banded charges based on the number of people in the household, 4) banded charges based on the type of property, and 5) banded charges based on property value. Research indicates that most successful rate models take variables from all five.

Discrete pricing in the form of block rate schedules are a popular methodology for utility rates. According to Taylor (1975), price is associated with the block where consumption as a marginal price and an average price. Block rate pricing allows municipalities to adjust utility rates for issues such as conservation or poverty.

In 1976, Nordin defined a linear demand function for water which included consideration of consumer income. In this case the difference between the marginal price and the price typically charges becomes a tariff for the community. However, this method is necessary to reduce costs on those who cannot afford to pay. At the same time an inclining block rate for conservation places a burden on those who utilize the most water in an effort to encourage reduce usage. Research indicates that most block models are dependent upon available data and can be biased or inconsistent (Deller, Chicoine, \& Ramamurthy, 1986). Their research suggests, although not conclusively, that instrumentation introduced by Judge, et.al, in 1986. This methodology provides a proxy for troublesome variables and reduces inconsistency in the data. Two specific instruments are suggested to remove data error bias in the 1986 study. Regardless of the demand model selected, care must be taken to remove bias due to inaccurate data.

Rate models are complex and there is no true cookie cutter model that fits all situations. To accomplish the four issues listed there are many considerations including conservation incentives, number of meters, size of meters, commercial and residential customers, administrative considerations, age of facilities, capital improvements, etc. Many of these issues include trade-offs for political or economic reasons. Building the most efficient and cost effective system is the municipalities goal, but strategic planning for future use must also be considered. A true decision support rate model will provide managers with options for each element of the model and support the mission of the organization.

A successful rate model must meet requirements of the political, financial, environmental, and strategic plan for the municipality it supports. It is extremely important that the governing body is aware of all cost associated with the operation and maintenance of the utility. Additionally, it is important that charges are appropriate and ratepayers, not general tax payers, cover all costs associated with the utility. According to Gerasimos and Wang (2003), the following goal development process must address;

1. Revenue Generation: the utility must cover its costs and by law can only exceed costs by a limited amount.

2. Cost Allocation: the structure for allocation of costs of uses and users.

3. Incentive Provision: the extent to which the utility will try to influence the behaviors of users through the rate structure.

4. Revenue Stability: the predictability and stability of the revenue flow.

5. Administrative Costs: the tradeoff between low administrative costs and a more complex rate structure.

6. Transparency: the pricing model must be understandable and provide a clear price signal.

7. Reliability: the system provides enough capacity for peak usage and expansion.

8. Affordability: the pricing model must be fair and equitable to all users and consider the extent of cross subsidies.

Rate studies are more than just a planning or finance document that aids in the decision making process. Among considerations include whether rates are distributed fairly among residential and commercial customers. It is important that accurate data is provided by the entity being evaluated and care must be taken to ensure that all expenses to the utility are truly related to the utility function as charged. Dialogue among organization leaders and the rate study team are an important issue in the planning process. A completed rate study serves as a planning methodology for future capital improvements and utility expansion.

A key tool in utility rate structuring is benchmarking with other agencies using similar utilities and a comparable customer base. However, it must be noted that all utilities are different in some respect and the model 
must ensure that each community's utilities are self-sufficient and meets the needs of the community. Additionally, many rate structures are structured differently based on the community's strategic plan or basic needs. Base rates and volume rates are structured differently in many communities and meter size varies from system to system. Additionally, the age of the system plays a key role in pricing.

A utility rate study is a road map for a designated period of time that helps planners make decisions for capital expansion, addition of new utilities, services provided to the community, and other key elements of the long term strategic plan. Rate studies are accomplished when necessary, but at a minimum when rate increases are anticipated. Additionally, a successful rate model can serve as a tool for what-if analysis by planners. In this instance, a capital improvement projection can be measured to determine impact on rates thus aiding the decision making process. Several questions must be answered prior to beginning a rate analysis. These include:

1. What will happen to the customer base over the term of the rate study? Will it increase or decrease? Is there anything projected that will change the customer base?

2. Will costs escalate over the rate study term? Are increases or decreases in labor, materials, services, or benefits anticipated?

3. Will staffing levels or organizational structure change over the rate period? What is the anticipated level of growth for the organization?

4. What staff outside of the utility department support water and sewer through a percentage of their jobs? What percentage and can it be justified?

5. What contribution will need to be made to utility reserves? What is necessary for emergencies?

6. What capital improvements are planned over the rate period?

7. What capital replacements are projected?

8. What debt service is associated with water and sewer? Are any bonds planned for the future or included in capital expansion or improvement?

It is important to remember that the main goal of a rate study is to ensure the utility is completely selfsufficient. Bond sales can be supported by utility rates, but it is important to note that each utility, water or wastewater, should be able to stand on its own. To dip into general funds to pay utility expenses would add an unfair element as non-users would be forced to pay for a service not rendered. The water and wastewater fund should balance at the end of each year.

\section{Utility Rates - Cape Coral Florida}

A consultant hired by Cape Coral to audit the City's Utilities Department identified perhaps the most difficult challenge facing City administrators (Raftelis Environmental Consulting Group, Inc., 1995). Establishing a shared community vision has been made difficult owing to the numerous interest groups in the City. Groups include homeowners and other residents; developers; owners of undeveloped residential, commercial, and resort properties; citizen groups, and multigenerational citizens. Each of these groups has its own financial, social, business, health, and security requirements. These differing requirements often translate into differing objectives, such that City leadership must be responsive to a diverse set of public needs.

As with most municipalities, utility rates in Cape Coral are a concern to citizens. The following few pages attempt to outline a few of the issues faced by a growing city. In 1995, data became a major issue as a much needed rate increase was voted down by Council due to numerous questions, many brought forward by citizens.

It is important to discuss this issue from a historical perspective. In 1988, Boyle Engineering Corporation, under contract with the City, developed a utility master plan, titled "Water Independence for Cape Coral," (WICC Plan). The highlight of this plan was the initiative to utilize reclaimed wastewater effluent, in combination with canal withdrawals, for irrigation and other non-potable uses. By providing an irrigation distribution system, the City reduced the demand on the aquifer thereby preserving and prolonging its life.

In 1991, the City of Cape Coral hired an engineering firm to conduct a utility rate update for the City water and wastewater utility system. The purpose of this paper is not to critique the report submitted by the engineering 
firm of Camp, Dresser, and McKee. No one can argue against the fact that the report was professionally prepared. Rather, the focus of this paper is on the forecasting of future revenues used as a basis for the study. Four issues contributed to the forecasting model used in the study producing inaccurate projections: (1) the City was installing 14 square miles of sewer system that was completed behind schedule; (2) the City was installing an irrigation system to homes. These accounts were added at a slower than anticipated pace; (3) the growth rate for the City was anticipated to continue at the $8 \%$ level experienced in the 1980s. In fact the rate dropped to approximately $3 \%$; and (4) the data provided by the City for water and sewer accounts were inaccurate.

According to the 1991 rate study based on account data provided by the City, water accounts were predicted to reach 28,979 and wastewater accounts 23,088 in 1992 . The City reported that actual water accounts for 1992 reached 37,098 while wastewater accounts rose to 23,705 . The study predicted that the City would make $\$ 15,470,594$ during that first year. Actual revenues were only $\$ 15,406,209$. The difference of $\$ 96,708$ for that first year was insignificant. However, the larger question is how revenues could be short at all when actual accounts appeared to exceed predicted accounts by such a significant margin.

The problem worsened in the second year as the real impact of a faulty forecast was realized. Projections for that year called for 35,327 water accounts and 25,009 wastewater accounts. City statistics for 1993 revealed that actual water accounts reached 38,315 while sewer accounts rose to 23,342. Projected revenues for 1993, based on the rate study were $\$ 19,147,161$. Actual utility revenues were $\$ 15,406,209$, representing a difference of $\$ 3,740,952$. Again, actual accounts appeared to exceed predicted accounts and, given the wide range of error in estimating revenues, there was substantial reason to doubt the ability of the forecasting study to accurately estimate utility revenues.

In 1994, City staff determined that the account data utilized in the 1991 study were flawed and corrected the account totals for future use. As evidence of how far the data were off, the 1991 study had predicted that the City would have 37,044 water accounts and 39,933 wastewater accounts in 1994. Using the 1994 adjusted data, the prediction was for 28,891 water accounts and 17,344 wastewater accounts. The actual figures for 1994 were 28,152 water accounts and 16,203 wastewater accounts. The inflated rate study projected $\$ 24,228,719$ in utility revenues for 1994. Actual revenues realized were $\$ 14,523,876$, almost $\$ 10$ million below the expected total.

The combination of erroneous data, slower than expected growth rate, slower than projected wastewater construction, and delays in securing irrigation connections created revenue flow problems for the City. Compounding the issue was the fact that City planners budgeted with the projected figures. In 1994, the City of Cape Coral allotted almost $\$ 1.6$ million more than actual revenues. The 1991 rate study, in its executive summary indicated that, "from projections of revenues and expenses at existing rates, the water system appears to be selfsufficient only through Fiscal Year 1992 in terms of meeting its operating revenue needs from the standpoint of debt coverage." As later facts became known, this turned out to be a true statement. The efficiency and effectiveness of the rate study were handicapped by the data used and thus by the forecasting model developed. Clearly, results from the 1991 rate study were flawed, leading to significant underestimating of revenues for City water, wastewater, and irrigation programs.

Growth in government means changes in processes and structure. While Cape Coral accomplished this strategically with forward thinking innovations such as a \$21 million Water Reclamation Plant, a \$125 million Gravity Sewer Project, and a $\$ 100$ million Dual Water System, the City's data collection system was not as responsive. In 1991, as the rate study was being conducted, the City realized that its computer system would be the key to a cost-effective solution to problems already identified with information processing, data collection and full integration of systems. A proposal was presented to the City Council to replace the WANG VS100 with an IBM AS400 and a fully integrated database provided by Harward Technical Enterprises (HTE). The Wang VS100 utilized a flat file database that required COBOL programmers to customize reports for management. It was adequate throughout the early history of Cape Coral, but not so for maintaining data for an enlarged city with a proactive strategic plan. The AS400 and the HTE software were chosen in 1992, but the implementation process extended into 1994. 
The City's first Business Manager was hired in January 1994. At that time, the utility module was not converted from the WANG system to the HTE system. A new utility rate study was commissioned in early 1994, but not completed until December of that year. Once completed, the new rate study was rejected by the City Council after many sessions of heated public debate. The discrepancies noted between the 1991 rate study and current data in 1994 proved to be confusing to citizen groups and City Council members. Basically, conversion of the WANG system to HTE highlighted data problems that contributed to inaccurate forecasting during the previous study. The Business Manager assumed responsibility for data conversion. It was apparent at an early stage that the HTE system was an outstanding system that would accomplish everything that the City needed in the area of data storage, management, and security. However, the HTE system was only as good as the data provided by the City and the previous system. Therefore, the first element of conversion became an analysis of data and processes. Through this process, several areas of concern developed.

Additionally, there were few processes in place that involved users in the storage and manipulation of data. This resulted in responsibility for data being maintained at a centralized level with few measurements in place for data accuracy. Additionally, property changes were the responsibility of Lee County. The County utilized a good system for joining and dividing property. However, once the action was accomplished, the County transferred the changes on a weekly basis to the City for inclusion in their database. There was no process in place for the data to be entered in the City's database; therefore, each week the data held by the City of Cape Coral were deteriorating.

Also, there was no accounts receivable database available for a water assessment. Citizens paid as they were connected and the results were logged, but not maintained so that they could be queried or analyzed. Several accounts, totaling approximately $\$ 65,000$ were not billed for their annual payment. In 1993, some 24 months later, the properties involved were assessed liens by the City but still not billed. In 1994, the accounts were billed by the incoming Business Manager. However, due to the liens not being placed until 1993, several properties had new owners. This caused a huge customer service problem. Additionally, the absence of a database resulted in several homes being missed and not connecting as legally required by City ordinance.

Finally, water and wastewater accounts and housing units were tracked by a report from the WANG system. Though this report was difficult to read, the 1991 report relied primarily on this historical data for its forecasting model. This customer data obtained from internal records proved to be the Achilles heel of the rate study. Data retrieved from historical files indicated that over time, City staff had erroneously transposed units and accounts. Each dwelling is considered a unit, while only the metered accounts are measurable for revenue purposes. The reporting system used by City staff consisted of reports from various internal forms that were consolidated in the Customer Service department on a written monthly report.

Compounding the issue was the fact that these reports to management were simply compiled on the monthly reporting sheet and then filed. Without the benefit of a spreadsheet, it was easy for management to miss the transposition of erroneous data. This caused customer complaints and data that were virtually useless for planning purposes. Since the reports were filed and not followed on a spreadsheet, the significant difference in the number of units was not discovered until the City converted to the new computer system in 1994.

The 1991 rate study predicted that the City would experience a 20\% reduction in water consumption due to the implementation of Water Independence for Cape Coral, the earlier report commissioned in 1988. This projection was built into the model, but did not compensate for erroneous data provided by the City. In 1994, the City Business Manager analyzed six months of water usage for the first 10,500 customers receiving the dual water system. This review determined that in a six-month window, 9,500 users having irrigation in 1994 and no irrigation in 1992 consumed 203 million fewer gallons of potable water. With a City average of 207 million gallons per month, this constitutes two full months of water and wastewater revenues with only $33 \%$ of the potential users connected. While this variable was considered, its effects on new irrigation revenues were considered to be minimal. Further analysis of accounts in preparation for the 1994 rate study revealed inaccuracies in approximately 8,000 water accounts and 5,000 wastewater accounts.

In 1991, the City was structured for a centralized information system division that allowed no ownership of data by the individual departments. As stated earlier, the MIS Manager and two programmers managed the WANG 
system. This was a system of centralization by necessity. The COBOL programming required to provide reports was complicated and cumbersome. While department managers controlled input through account entry at the various service counters, very little control over or responsibility for data was provided to department managers. Therefore, many of the data entry requirements fell on the MIS division. Managers requiring reports would request the necessary data through the programmer and wait on results. Due to the complexity of the COBOL programming, managers had to assume that the programmer understood the requirements.

Responsibility for data and processes was placed at the lowest level rather than with senior management. The engineering firm was provided data by a divisional supervisor based on reports provided by the MIS division. Measurement and accuracy checks were not in place at higher levels of the organization.

The rate study conducted in 1994 was ultimately rejected in the face of problems realized with the earlier study. In addition to inaccuracies identified in the data provided for the 1991 study, citizens blamed City officials for delays in ongoing projects and voted the 1994 study down. The City began to explore the various reasons given for the study's rejection and in early 1995, realized that implementing a new computer system was not the complete answer to data accuracy. A new City Department, the Office for Business Management and Information (OBMI), was formed from the existing Business Office and the MIS Division of General Services. This allowed the processes of revenue collection to be integrated with the implementation of the new computer system.

Understanding that the problems with the rejected 1994 rate study were not due to the methodology utilized by the engineering firm, but due to the data provided by the City, managers embarked on several changes to strengthen future rate models. First, the City fast tracked the conversion to the HTE system. The City's implementation of the utility module of the HTE system was delayed during the initial phase due to implementation concerns. Data provided to the engineering firm were from the WANG system that was running simultaneously during conversion. Conversion of revenue data was given new emphasis and authority under the responsibility of OBMI. The City created the Office for Business Management and Information (OBMI) by combining offices of Utility Customer Service, Assessment Billing, Lot Mowing Billing, Stormwater Billing, and the MIS Division of General Services. With the exception of MIS, all of these offices were divisions of the Utilities Department. The City's creation of OBMI allowed for centralization of the data process engineering.

Further, the Accounts Reconciliation Project was developed by the Business Manager as a task force to analyze data and assign responsibility. This project was established to assign responsibility for data. Each process was flowcharted by teams of individuals that were involved with the collection, processing, storage, and analysis of data. Once complete, responsibility and accountability measures were implemented to ensure accurate data throughout each City department. The Raftilis Study (1995-1996) was commissioned to analyze utility operations and provide an operational look at City utilities. Finally, a group of volunteer citizens formed an ad-hoc committee to analyze City utility operations. This watchdog group evaluated past City processes to determine if the best interests of the City were considered during each transaction.

The final result of these changes was that forecasting for future utility needs became easier due to improved data. In response to revenues being underestimated, the City eliminated several capital projects that were planned. By reducing current spending levels, the City managed current operations without funding from the 1994 rate study. However, significant amounts of money and man-hours were wasted due to inaccurate data.

Working closely with the Finance Director, the Director of OBMI provided forecasting data for budgeting purposes that proved accurate during FY 1995 and FY 1996. However, because the City had not raised rates in FY 1995 as proposed, the self-sufficiency of City utilities was jeopardized. The Department of Public Works Director wrote in late 1995 that City utility rates should be raised "to make necessary repairs to our collection system and provide a connection which will allow us to divert sewage from the southwest section of town to the Southwest Reclamation Facility (SWWRF) for treatment."

As noted at the beginning of this section, the 1994 utility rate study was not approved by the City Council due to the many questions raised by community activists during the public hearings. The study was not successful due to the many "pitfalls in forecasting." Insufficient and inaccurate data due to inadequate structure and processes 
made forecasting for an accurate utility rate extremely difficult. The result was obviously a study that did not respond to the needs of City management.

Despite significant problems associated with erroneous data, there were elements of the rate study project that were positive. For example, successful forecasts require that the forecaster show that the project will improve operations in accordance with the needs of management. This project clearly set out to produce accurate estimates of revenues to be collected to facilitate management's budgeting for water, wastewater, and irrigation projects. In addition, forecasters must work carefully with management in order to lead to results that will meet management's goals. To this end, CDM representatives met regularly with City officials and staff to ensure that the project remained on track and that both sides were informed of the project's progress. These discussions were important since City representatives were not experts at forecasting.

A key element in forecasting is the time frame in which data are collected and analyzed in comparison to the time frame for the forecasting. Data used in 1991 were on a short time frame since the City's computer system only held 90 days worth of data. This was an acceptable range since the study was needed relatively soon after it was commissioned. An apparent weakness, however, is the fact that no trend or time series analysis could be conducted on data obtained for such a short time frame. This diminished the ability of the forecaster to anticipate other potential outcomes since a valuable point of reference was lost.

Successful forecasts result when forecasters understand the culture and operational goals of the organization. In retrospect, it seems apparent that this is the point at which things began to go awry. The forecasters did not go so far as to put themselves in management's shoes. The right questions were never asked and vital information was not shared. CDM began analyzing data provided by the City in blind acceptance that the data were accurate.

The City of Cape Coral rebounded from its forecasting failure in 1991. In 1995 the annual report of Cape Coral's water and wastewater system described the City's systems at that time. The City water system included 24 raw water supply wells, 6 miles of raw transmission mains, a reverse osmosis water treatment plant, associated brine disposal system, two storage and repump stations, 540 miles of potable water mains, and 450 miles of irrigation (reuse) mains (Hartman \& Associates, Inc., 1995).

At that time, and continuing until today, Cape Coral has one of the largest operating reverse osmosis plants in the country. With a rated capacity of 15 million gallons per day (mgd) of potable water, the system provides Cape Coral with reliable flow of purified drinking water, drawn from the aquifer deep beneath the city. Current consumption is about half of the plant's current capacity, promising that the community's water needs will be met easily for years to come.

In 1995, the City's system for reclaimed water included 400 miles of gravity sewer mains, 6,339 manholes, 170 lift stations, 48 miles of force mains, two water reclamation facilities, and an irrigation system for water reuse and effluent disposal. The irrigation system included 450 miles of water reuse mains, two storage and pump stations located at the water reclamation facilities, and five canal pump stations (Hartman \& Associates, Inc., 1995).

To further assure plenty of pure potable water to its businesses and residents, Cape Coral introduced one of America's first, largest, lowest costs, and most successful, residential dual water systems. A separate system reclaims and recycles domestic wastewater, adds water from fresh-water canals, and distributes the water exclusively for irrigation and fire fighting.

In 1996, City Council and staff recognized the need to update the WICC Plan, as sound engineering judgments for the future needed to be based on current data rather than assumptions made the previous decade. To this end, the City engaged Dames \& Moore to update the existing WICC Plan. Their scope of work involved three distinct phases: Initial Planning, Engineering Planning and Update of the Master Plan. This effort was completed in October/November 1998. 
The initial planning phase consisted of a tremendous data collection effort to establish existing utility, financial and local conditions. All pertinent information was collected, catalogued, stored and managed in a GIS database. The key products of this phase were the development of hydraulic models for the potable water, wastewater and secondary systems. Field calibration of these models was also accomplished to ensure that predicted modeled values were closely correlated with actual outcomes.

The engineering planning phase of the project involved the development of the next utilities expansion areas. To do this, Dames \& Moore, together with a team from the City, distilled and refined a set of engineering planning criteria against which non-served units of the City would be evaluated. The criteria included: projected density, land value, rate of growth, proximity to existing utilities, groundwater protection, surface water effects, economic development, land use conformance, existing utility availability, and planned capital improvements.

All areas of the City were evaluated against these criteria resulting in the identification of units which appeared to merit expansion. Given these interim results, a financial feasibility review was applied to further narrow the candidate units for new utilities. The outcome derived from this process pretty much validated the Council's initial assessment of what the next expansion areas should be. That is, the Pine Island Corridor, an area in the northeast (Purple area as designated on the City planning map), and the rapidly developing Southwest area.

This master plan phase of the project will provide the utilities "road map" to the future. The initial look at the future will be at 2002, then 2005, 2010, 2020 and build out. At build out, the population of the City is projected to be approximately 400,000 people. Sizing of utility lines at build out has been determined as well as at 2020 . With the results of the Utilities Master Plan Update, the City's utilities expansion will be planned to be efficient and orderly thereby assuring the continued growth and stability of Cape Coral.

Due to the public hearing process, the City of Cape Coral learned a valuable lesson about accurate forecasting. The 1991 rate study produced a false target resulting in overspending by City government and the need for a utility hike in 1994. Inaccurate data and the inability to explain the deficiencies, led to mistrust of government staff and the voting down of the 1994 rate study. During the public hearings, citizens were blaming everything from expensive supplies to government corruption as the problem. Laubach (1995) wrote an article titled "City Utilities Losing \$200,000 a Month" in which a quote from then Public Service Director places the blame for the losses with the predictions made for the 1991 utility rate study and delays in the wastewater project. The debate over utility rates resulted in demands by City Council members for audits of the entire system. City Council voted to delay any rate increase until a determination of cause could be established.

Based on citizen opposition, rate increases requested and needed in 1995 were not approved until much later. As noted throughout the historical analysis of rates at the time, the City spent to the 1991 projections and now in a financial bind without requested rates. In fact, as noted earlier, rumors circulated indicating that the City was losing $\$ 200,000$ per month and the question was ask during a February 27, 1995 public hearing. The following is a quote from a report by contractor Camp Dresser and McKee, Inc. sent to the Utility Director on May 22, 1995.

"Current revenue is approximately \$200,000 less a month than the City's projected expenditures for fiscal year 1994/1995. The 1994 rates were not sufficient to cover operating costs in 1994 and 1995 due to the following factors: the number of customer accounts was overstated due to a programming error; the growth rate projected by the City in the 1991 Rate Study was not realized; the debt service increased for the southwest plant and transmission system due to higher interest rates; and water consumption was less than anticipated due to the use of reuse water. Projections and assumptions are estimates arising from historical usage and available data."(CDM memorandum, May 22, 1995)

To this point, this case centers on water and wastewater utilities. Irrigation in Cape Coral is, and has been leading edge technology but not without controversy. The chart below demonstrates how the 1994 rate proposal suggested raising irrigation rates for the first time. Citizens were promised $\$ 5$ per month for life for a residential home when the system was approved in 1988. While City Council should not have promised something this hard to deliver, citizens expected compliance. This rate study represented the first time a raise was suggested, thus adding to opposition. At this writing the irrigation rate is $\$ 9.50$ per month for residential irrigation water regardless of usage. A bargain, but not $\$ 5$ for life as promised. 
As noted, utility rates have continued to be a concern for citizens. Fast forward to 2009 and the City is involved in a new controversy; a huge increase in utility rates due to a stoppage in utility expansion and the need to pay for new facilities. On May 19, 2009, Cape Coral's City Council passed resolution 13-09. As noted in the charts below, this resolution raised utility rates significantly to pay for expansion of facilities and debt service largely associated with delayed new utility service areas.

In a March 23, 2009 memorandum to the Mayor and City Council, the Finance Director explained that the 2006 rate adjustment program was based on projected hookups from completion of the Utilities Expansion Program (UEP). In May 2008, City staff presented an analysis stating that the City is in danger of not meeting requirements for its bond covenants for the fiscal year 2008 due to issues facing the UEP. Bond covenants require that the City collect enough from water and sewer to cover debt service by a minimum of 1.0 times. To ensure compliance, City staff managed revenues to ensure that bond covenants would be met. Staff feels confident that bond covenants will be met in 2009, but 2010 and beyond were in jeopardy. To combat this possibility, staff contracted Burton and Associates to update the May 2008 utility rate study and provide scenarios for City Council to consider that would assure successful bond covenant coverage (Finance Director Memorandum, March 23, 2009).

In the March 23, 2009 memorandum, the Finance Director indicated that the economic slowdown caused a downturn in projected utility hookups. Additionally, recent City Council action halting the UEP created pressure on the financial system. Staff recommended that utility rates be adjusted to reflect revised connection estimates. This memorandum proposed several scenarios to be considered by City Council. Rates, according to the memorandum, are based a series of assumptions. Issues such as future projections, capital improvement program, operating expenses, capital expansion fees, and debt issues are dependent upon market conditions. Recent market adjustments dictate that the City review and change its rate plan to meet future obligations. The following scenarios were submitted to City Council.

The Finance Director presented three scenarios (Memo, March 23, 2009) for City Council to consider in an effort to ensure that the City would meet debt obligations in 2010. According to the memorandum, doing nothing would result in several negative actions including failure to meet bond covenants and reduced funds to meet operations and capital obligations. Scenario 1, listed below required no further action in the UEP and increased rates the most for citizens currently on the system.

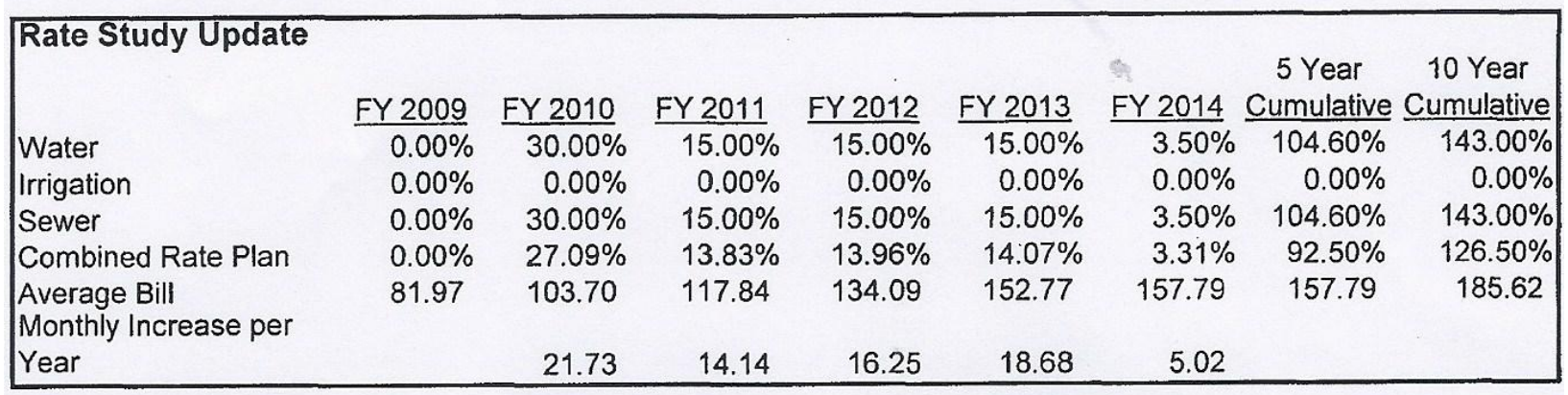

Source: Finance Director Memorandum to Mayor and Council, March 23, 2009.

Under this scenario, rates increase $30 \%$ in the first year and progressively increase over a five year period to $104 \%$ from the 2009 level. Scenario 2, shown below, allows for water to be extended to utility area North 1 to 8 and provides an $18 \%$ increase in 2010 . This scenario provides for a $62 \%$ increase over a five year period. 


\begin{tabular}{|c|c|c|c|c|c|c|c|c|}
\hline \multicolumn{9}{|c|}{ Informational Item 1 -Water Only UEP in North 1 - 8} \\
\hline & FY 2009 & FY 2010 & FY 2011 & FY 2012 & FY 2013 & FY 2014 & Cumulative & $\begin{array}{l}10 \text { Year } \\
\text { Cumulative }\end{array}$ \\
\hline Water & $0.00 \%$ & $23.00 \%$ & $8.50 \%$ & $8.50 \%$ & $8.50 \%$ & $3.50 \%$ & $62.60 \%$ & $93.10 \%$ \\
\hline Irrigation & $0.00 \%$ & $0.00 \%$ & $0.00 \%$ & $0.00 \%$ & $0.00 \%$ & $0.00 \%$ & $0.00 \%$ & $0.00 \%$ \\
\hline Sewer & $0.00 \%$ & $23: 00 \%$ & $8.50 \%$ & $8.50 \%$ & $8: 50 \%$ & $3.50 \%$ & $62.60 \%$ & $93.10 \%$ \\
\hline Combined Rate Plan & $0.00 \%$ & $20: 82 \%$ & $7.86 \%$ & $7.90 \%$ & $7.94 \%$ & $3.29 \%$ & $55.30 \%$ & $82.30 \%$ \\
\hline $\begin{array}{l}\text { Average Bill } \\
\text { Monthly Increase per }\end{array}$ & 81.97 & 98.63 & 106.21 & 114.43 & 123.35 & 127.33 & 127.33 & 149.45 \\
\hline Year & & 16.66 & 7.58 & 8.22 & 8.92 & 3.98 & & \\
\hline
\end{tabular}

Source: Finance Director Memorandum to Mayor and Council, March 23, 2009.

Under scenario 3, the UEP would continue with all services to utility are SW 6/7 and water only to utility area North $1-8$. The results, listed below, raise rates $18 \%$ in 2010 and have a five year cumulative effect of $53 \%$.

\begin{tabular}{|c|c|c|c|c|c|c|c|c|}
\hline Informational Item 2 & Water $\mathrm{C}$ & UEP & $\operatorname{Prth}=1$ & $\mathrm{AII} \mathrm{SE}$ & III & & $5 \mathrm{Ye}$ & 10 Year \\
\hline & FY 2009 & FY 2010 & FY 2011 & FY 2012 & FY 2013 & FY 2014 & Cumulative & Cumulative \\
\hline Water & $0.00 \%$ & $18: 00 \%$ & $8.00 \%$ & $8.00 \%$ & $8.00 \%$ & $3.50 \%$ & $53.80 \%$ & $82.70 \%$ \\
\hline Irrigation & $0.00 \%$ & $0.00 \%$ & $0.00 \%$ & $0.00 \%$ & $0.00 \%$ & $0: 00 \%$ & $0.00 \%$ & $0.00 \%$ \\
\hline Sewer & $0.00 \%$ & $18.00 \%$ & $8.00 \%$ & $8.00 \%$ & $8.00 \%$ & $3.50 \%$ & $53.80 \%$ & $82.70 \%$ \\
\hline Combined Rate Plan & $0.00 \%$ & $16.25 \%$ & $7.35 \%$ & $7.40 \%$ & $7.43 \%$ & $3.27 \%$ & $47.60 \%$ & $73: 10 \%$ \\
\hline $\begin{array}{l}\text { Average Bill } \\
\text { Monthly Increase per }\end{array}$ & 81.97 & 95.01 & $\cdot 101: 85$ & 109.24 & 117.22 & 120.99 & 120.99 & 141.91 \\
\hline Year & & 13.04 & 6.84 & 7.39 & 7.98 & 3.77 & & \\
\hline
\end{tabular}

Source: Finance Director Memorandum to Mayor and Council, March 23, 2009.

On May 19, 2009, under City Resolution 13-09, City Council adopted scenario number 1. This scenario requires current rate payers to pay for facilities and debt incurred for UEP projects. This was not accepted very well by the public.

The City of Cape Coral utilizes a utility rate study, commonly completed by an outside consultant, to identify utility rate requirements. Utility Rate studies for water and sewer are commonly utilized by cities and counties to determine the appropriate rate to be charged for services. These rate studies are demand models that consider numerous variables that consider various influences to determine an optimal pricing strategy. This study examines the elements of a utility rate model that are used to create an economic, environmental, and equity balance for governmental agencies trying to serve the public and maintain a fair price for services. This research will include publicly operated water and wastewater considerations as we analyze the elements of a rate model.

Determining utility rates is an important element in the decision making process for government agencies. To that end, a good rate model is easily completed and monitored by the staff of the organizations they support. However, usually due to overall costs or civic mistrust in government, rate models are often completed by consultants to justify any proposed rate increase. It is not unusual for municipalities to hire short-term expertise to complete projects where permanently the hiring the human resources cannot be justified. In reality, there are many pitfalls to rate modeling and statistics can be manipulated to meet the needs of the analyst. This research will also explore some grey areas in rate modeling.

The ability to forecast future growth and consumption is another critical element of a rate model that is often minimized or overlooked. As noted earlier, in 1995, a rate study by the City of Cape Coral Florida was rejected by City Council after opposition from citizens. The problem stemmed from erroneous data in a 1991 rate study that enabled revenues to be approximately $\$ 10$ million or 40 percent, below projections by the time a followup study was contracted (Anderson and Forrer, 2001). 


\section{CONCLUSION}

This research is a base document to support future research in the area of water and wastewater utility pricing. The paper attempts to identify elements of the demand function and pricing methodology that affects utility pricing. While it is virtually impossible to cover every model and variable in a short paper, this research identifies the basic elements of a utility rate study. Future research will explore individual pricing and demand models in an attempt to develop an optimal water and wastewater pricing model.

The main pricing variable is the block structure utilized by many municipalities when determining utility charges. Shinn (1985) indicated that consumers are not really sure whether they are looking at marginal costs or average prices. Municipalities use increasing or decreasing block pricing dependent upon the political and environmental issues they must address. Consumer perception of financial models may be based on biased information. It is extremely difficult for a consumer to read his/her meter and follow consumption on a monthly basis. Therefore, consumers may not completely understand the price of the utility.

It is imperative that municipalities build a rate model that addresses variables important to the community they serve. Due to the vast environmental differences, there are no "one size fits all" rate models. Rate models must be carefully crafted and communicated to consumers in term they understand. Cape Coral is no exception.

\section{AUTHOR INFORMATION}

Dr. Don Forrer serves as Professor at Hodges University in Naples Florida. Dr. Forrer serves as a consultant to government and small businesses. Don serves as the President of his consulting firm "Cybernetic Concepts". The firm specializes in water and sewer rates and charges. He is a member of the Rates and Charges committee of the American Water Works Association (AWWA). This prestigious committee writes the M1 manual that establishes water and wastewater rates/charges for the industry. Dr Forrer's area of research is utility economics where he has presented and published numerous papers. Dr. Forrer has also authored two books.

Dr. Charles Ehart is an Associate Professor of Public Administration for Hodge University and has taught graduate level courses in public administration and management since 1993. He also does work as a consultant in management and alcohol regulation. Dr. Ehart retired in 2003 as an Assistant State Comptroller with the State of Maryland, and served as the Director of the Alcohol and Tobacco Tax Division. In this capacity he was responsible for regulating the alcoholic beverages and tobacco industries in the state and collecting the excise tax on distilled spirits, beer, wine, cigarettes, and other tobacco products.

Acie Forrer (Doctoral Student) consults for an investment banking firm located in Naples Florida and specializes in underwriting and negotiating complex commercial loan relationships. Additionally, Acie is a full time Doctorate student at the University of Maryland - University College and teaches as an adjunct faculty member of Colorado Technical University and Everglades University. Acie spent 14 years in banking where he specialized in commercial and executive banking. Acie received an undergraduate degree in Business Administration with a minor in Economics from the University of South Florida and a Master's in Management from Troy University. Acie has two daughters, Chelsea and Morgan, and coaches both in soccer.

\section{REFERENCES}

1. Anderson, T.A., \& Forrer, D. A., (2001). A comparative analysis of utility rate forecasting: The Cape Coral experience. Proceedings from the Production and Operations Management Society Conference, Orlando, Florida.

2. Bauman, D. D., Boland, J.J., \& Hanemann, W.M., (1998) Urban water demand management and planning. New York: McGraw-Hill, Inc.

3. CDM Memorandum to Cape Coral Utility Department, (May22, 1995), Cape Coral Rate Study, CDM Project/DCN: 6704-120-RT-REP.

4. Deller, S., Chicoine, D.L., \& Ramamurthy, G., (Oct 1986). Instrument variables approach to rural water service demand. Southern Economic Journal (1986-1998). 53, 2, p.333. 
5. Finance Director, (March 23, 2009, "Water \& Wastewater Rate Update Analysis - Supplemental to Rate Study Update", City of Cape Coral Financial Services Department.

6. Hartman \& Associates, Inc. (1995). City of Cape Coral: Water and wastewater annual report fiscal year 1995, Hai Project No. 96-347.00, Fort Myers, FL: Author, (1995).

7. Gerasimos A Gianakis, XiaoHu Wang. (2003). Procuring expertise: The case of local government water and sewer rate analyses. Journal of Public Procurement, 3(2), 250-273.

8. Judge, G. R., Hill, C., Griffith W., Lutkepol, H., \& Lee, T. (1982). Introduction to the theory and practice of econometrics. New York N.Y.: John Wiley and Sons.

9. Laubach, D., "City utilities losing \$200,000 a month", Cape Coral Daily Breeze, (February 15, 1995).

10. Nieswiadomy, M.L., \& Molina, D.J., (Aug., 1991). A note on price perception in water demand models. Land Economics 67, 3, p. 352.

11. Nordin, John A., (Autumn 1976). A proposed modification to Taylor's demand analysis comment. The Bell Journal of Economics. p. 719 - 721.

12. Raftelis Environmental Consulting Group, Inc., City of Cape Coral: Performance audit of utilities division, Charlotte, NC: Author, (1995).

13. Rajah, N., \& Smith S., (Aug. 1993). Distributional aspects of household water charges. Fiscal Studies. Vol. 14 , no. 3, pp. $86-108$.

14. Shinn, J., (Nov.,1985). Perception of price when information is costly: Evidence from residential electricity demand. Review of Economics and Statistics 67, pp. 591 - 598.

15. Taylor, L.D., (Spring, 1975). The demand for electricity: A survey. The Bell Journal of Economics. p. 74110 . 